\title{
Changes in glucose metabolism after distal pancreatectomy: a nationwide database study
}

\author{
Jin-Ming Wu ${ }^{1, *}$, Te-Wei Ho ${ }^{1,}{ }^{*}$, Ching-Yao Yang ${ }^{1}$, Po-Huang Lee ${ }^{1}$ and Yu-Wen Tien ${ }^{1}$ \\ ${ }^{1}$ Department of Surgery, National Taiwan University Hospital and National Taiwan University College of Medicine, Taipei, \\ Taiwan, ROC \\ *These authors equally contributed to this work \\ Correspondence to: Yu-Wen Tien, email: ywtien5106@ntu.edu.tw \\ Keywords: distal pancreatectomy; chronic pancreatitis; dyslipidemia; glucose metabolism; nationwide database \\ Received: June 27, $2017 \quad$ Accepted: January 19, $2018 \quad$ Published: January 27, 2018 \\ Copyright: Wu et al. This is an open-access article distributed under the terms of the Creative Commons Attribution License 3.0 \\ (CC BY 3.0), which permits unrestricted use, distribution, and reproduction in any medium, provided the original author and source \\ are credited.
}

\section{ABSTRACT}

Background. This population-based study evaluated changes in glucose metabolism after distal pancreatectomy (DP).

Methods. Data from the Taiwan National Health Insurance Research Database was collected from 2001 to 2010. Of 1,980 patients who underwent DP, 507 had diabetes and 1,410 did not.

Results. Of the 1,410 non-diabetic pre-DP patients, $312(22.1 \%)$ developed newly-diagnosed diabetes after DP. Multiple logistic regression analysis revealed that dyslipidemia $[$ hazard ratio $=1.940 ; 95 \%$ confidence interval $=1.362-2.763$; $P<0.001$ ] and chronic pancreatitis (hazard ratio $=2.428 ; 95 \%$ confidence interval $=1.889-3.121 ; P<0.001)$ were significantly associated with the development of diabetes after DP. On the other hand, analysis of changes in glucose metabolism among 289 pre-DP diabetes without the use of insulin revealed that $173(59.9 \%)$ had deteriorated glucose metabolism after DP.

Conclusion. Dyslipidemia and chronic pancreatitis are risk factors for the development of diabetes. Further, more than half of the pre-DP diabetes patients without the use of insulin had deterioration of glucose metabolism after DP. Therefore, clinicians should monitor glucose metabolism and clinical symptoms of hyperglycemia among DP patients.

\section{INTRODUCTION}

Distal pancreatectomy (DP) is the standard surgical procedure for resection of neoplastic and non-neoplastic lesions of the pancreatic body and tail [1]. The number of DP procedures has recently increased because of improvements in the detection of cystic and borderline pancreatic neoplasms (most develop in the distal pancreas) $[2,3]$, and increase in the indications of pancreatic surgery for benign or low-grade malignant tumors [4]. In addition, DP can provide relief from pain associated with chronic pancreatitis (CP) in the left pancreas and thus improve quality of life [5].
The pancreas plays a major role in glucose metabolism via endocrine hormones and secretes various digestive juices into the duodenum as an exocrine gland [6]. As such, DP may result in deterioration of glucose homeostasis and exocrine pancreatic insufficiency (EPI) because of the loss of the pancreatic parenchyma. Pancreatectomy-associated diabetes mellitus (DM) is defined as the onset of DM after pancreatectomy (pancreatogenic DM). The American Diabetes Association classifies this type of DM as "other specific type of diabetes mellitus" [7]. The rates of pancreatogenic (type 3c) DM vary from $9 \%$ to $39 \%$, depending on the extent of DP as well as the underlying disease $[1,8]$. Moreover, 
associated EPI after pancreatectomy may result in the deterioration of nutritional status, which in turn deteriorates glucose metabolism [9].

The incidence of pancreatic endocrine insufficiency after DP may increase because the follow-up period after surgery becomes longer, and more DPs are being performed for non-malignant diseases in younger patients who have long life expectancy. In addition, DP performed for CP may be associated with a higher incidence of pancreatic insufficiency due to the loss of pancreatic tissues and previous/ongoing damage to the residual pancreatic parenchyma [10]. However, some reports have indicated that many patients have normal fasting postoperative blood glucose levels after DP and there is little effect on pancreatic exocrine function $[5,11]$. Furthermore, the pre-DP DM subjects may experience deterioration of glucose metabolism after DP because of the loss of pancreatic parenchyma. To date, few studies have investigated the incidence of post-DP pancreatogenic $\mathrm{DM}$ after resection of benign or malignant pancreatic diseases with a long follow-up period.

The purpose of this study was to retrospectively examine the long-term changes in pancreatic endocrine function after DP using data from the Taiwan National Health Insurance Research Database (NHIRD).

\section{RESULTS}

\section{Incidence of endocrine pancreatic insufficiency in non-DM subjects after DP}

Among the 1,410 patients who underwent DP, 312 (22.1\%) were newly diagnosed with pancreatic endocrine insufficiency postoperatively. In this study, there were 65.2 per 1000 person-years of newly-diagnosed diabetes in patients with DP, which is considerably higher than that in the general Taiwanese population (with an incidence of 7.6 per 1000 person-years) $[12,13]$. The results of the univariate comparisons of patients with and without pancreatic endocrine insufficiency after DP are shown in Table 1. Patients who developed DM after DP were more likely to be male $(P=0.047)$, have dyslipidemia $(P<$ $0.001)$, and have $\mathrm{CP}(P<0.001)$. Cox logistic regression analysis showed that dyslipidemia $(\mathrm{HR}=1.940 ; 95 \% \mathrm{CI}$ $=1.362-2.763 ; P<0.001)$ and $\mathrm{CP}(\mathrm{HR}=2.428 ; 95 \% \mathrm{CI}$ $=1.889-3.121 ; P<0.001)$ were significantly associated with pancreatic endocrine insufficiency after DP (Table 2). Further, proportion of patients with endocrine insufficiency requiring OHAs and insulin in pre-DP nonDM subjects by time after DP was shown in Figure 1.

\section{Deterioration of glucose metabolism in DM subjects without insulin use}

Of the 289 patients with pre-DP DM without the use of insulin, 47 were treated with an AHM and 242 with
OHAs. Overall, deterioration of glucose metabolism after DP was observed in 173 patients (59.9\%), including 21 (45\%) who received no AHM and $152(63 \%)$ who were treated with OHAs (Figure 2).

\section{DISCUSSION}

This study found that $22.1 \%$ of patients who underwent DP developed DM. CP and dyslipidemia are two significant factors contributing to post-DP pancreatic endocrine insufficiency. CP is a disease characterized by progressive pancreatic inflammation and fibrotic injury, causing irreversible parenchymal damage and resulting in loss of endocrine and exocrine function [14]. Furthermore, pancreatic resection for $\mathrm{CP}$ further deteriorates glucose metabolism, which is clearly associated with the extent of parenchyma resection and also with the progression of underlying pancreatitis [15]. Compared to DP for CP, resection of pancreatic tumors apparently is associated with a lower incidence of endocrine dysfunction. The rate of new-onset DM after DP in patients without pancreatitis is relatively low, at approximately $5 \%-9 \%[1,11,16]$. For patients with $\mathrm{CP}$, the reported risk of DM after DP is around $22 \%-50 \%$, which is similar to our findings $[5,17-19]$.

In addition, the results of this study showed that dyslipidemia is a risk factor for post-DP DM. Dyslipidemia is a risk factor for the development of nonalcoholic fatty pancreas disease, which may reduce $\beta$-cell function, probably via lipotoxicity [20]. Some clinical studies support the association between a fatty pancreas and an increased risk of DM [21, 22]. In contrast, other studies, in which computed tomography was used to assess the severity of fatty pancreas, do not support the association between a fatty pancreas and DM [23, 24]. These inconsistent findings may be related to the definition of a fatty pancreas based on the imaging method, race, duration of follow-up, and associated metabolic syndromes [25].

Furthermore, changes in glucose metabolism of preDP DM without the use of insulin were analyzed, which showed deterioration of glucose metabolism in $59.9 \%$ of patients after DP. Although such cases were anticipated to have relative dysfunction of glucose metabolism before DP, the deterioration of glucose metabolism was clinically significant afterward, thus clinicians should inform patients of this information, closely monitor blood sugar parameters, and appropriately adjust anti-hyperglycemic strategies.

In our report, some demographics are different from other studies, and the reasons are illustrated below. First, the mean age is 51.5 years, which is a relatively young population. The mean age of the patients with distal pancreatectomy (DP) in the National Surgical Quality Improvement Project (USA) and in the Surveillance Epidemiology and End Results was 61.6 and 63.4 years, respectively [26]. According to one Taiwan population study, more than $60 \%$ of patients with newly-diagnosed 
Table 1: Univariate analysis of the influence of demographic and clinical characteristics on endocrine pancreatic insufficiency after distal pancreatectomy

\begin{tabular}{|c|c|c|c|c|}
\hline & $\begin{array}{c}\text { Total } \\
(N=1410) \\
\end{array}$ & $\begin{array}{c}\text { Non-DM } \\
(n=1,098)\end{array}$ & $\begin{array}{c}\text { DM } \\
(n=312)\end{array}$ & $P$ value \\
\hline Female & $677(48)$ & $543(50)$ & $134(43)$ & .047 \\
\hline Age group (y) & & & & .337 \\
\hline$\leq 49$ & $685(49)$ & $543(50)$ & $142(46)$ & \\
\hline $50-64$ & $390(28)$ & $294(27)$ & $96(31)$ & \\
\hline$\geq 65$ & $335(24)$ & $261(24)$ & $74(24)$ & \\
\hline Age (y) & $51.5 \pm 16.3$ & $51.0 \pm 16.6$ & $52.9 \pm 15.2$ & .056 \\
\hline Concomitant splenectomy & $266(19)$ & $208(19)$ & $58(19)$ & .935 \\
\hline Charlson comorbidity index & & & & .459 \\
\hline $0-1$ & $486(35)$ & $373(34)$ & $113(36)$ & \\
\hline$\geq 2$ & $924(66)$ & $725(66)$ & $199(64)$ & \\
\hline \multicolumn{5}{|l|}{ Comorbidity } \\
\hline Peptic ulcer disease & $729(52)$ & $552(50)$ & $177(57)$ & .057 \\
\hline Hypertension & $390(28)$ & $293(27)$ & $97(31)$ & .062 \\
\hline Dyslipidemia & $95(7)$ & $59(5)$ & $36(12)$ & $<.001$ \\
\hline Chronic pancreatitis & $245(17)$ & $142(13)$ & $103(33)$ & $<.001$ \\
\hline Renal failure & $32(2)$ & $21(2)$ & $11(4)$ & .128 \\
\hline Indication for DP & & & & .393 \\
\hline Pancreatic cancer & $186(13)$ & $140(13)$ & $46(15)$ & \\
\hline Other causes & $1224(87)$ & $958(87)$ & $266(85)$ & \\
\hline Monthly income (NT\$) & & & & .080 \\
\hline$\leq 22,798$ & $806(57)$ & $614(56)$ & $192(62)$ & \\
\hline$>22,798$ & $604(43)$ & $484(44)$ & $120(39)$ & \\
\hline \multicolumn{5}{|l|}{$\begin{array}{l}\text { Duration of follow-up } \\
\text { (months) }\end{array}$} \\
\hline Median (IQR) & $37.8(18.7-73.0)$ & $33.8(17.3-66.7)$ & $59.2(25.9-96.2)$ & $<.001$ \\
\hline Mean, log-rank & $48.7 \pm 35.4$ & $44.7 \pm 33.4$ & $63.0 \pm 38.4$ & $<.001$ \\
\hline
\end{tabular}

DM, diabetes mellitus; IQR, interquartile range.

Age data are presented as the mean \pm standard deviation and other data as the number (percentage).

diabetes were aged $>60$ years [12]. To investigate changes in glucose metabolism, we only enrolled individuals without diabetes. Because of this, our cohort was likely younger than other population studies that focused on a broader sample of patients with DP. Second, half of patients had peptic ulcer disease in this cohort. One study determined that gastric ulcers increased the risk of pancreatic cancer during an 18-year follow-up period [27]. In addition, most patients who undergo DP also receive a gastroduodenoscopic examination or endoscopic ultrasound to do biopsy of the pancreatic tumor or to gain information regarding the character of the tumor. Occult cases of PUD may be diagnosed via endoscopic examination. Furthermore, some cases of DP were associated with multiple endocrine neoplasm syndromes, which may result in peptic ulcer diseases, particularly in cases with gastrinoma. We believe these are the reasons for the high observed incidence of peptic ulcer disease in this study cohort. Third, only $7 \%$ population had dyslipidemia. Obesity is not a common disorder in Taiwan; therefore, dyslipidemia (a metabolic syndrome) is also not as common as it is in Western countries. Approximately $15 \%-30 \%$ of Taiwanese individuals are diagnosed with dyslipidemia, depending on age and gender. Moreover, the subjects with pancreatic neoplasms may have cancer cachexia, which causes body weight loss and nutritional status deterioration. Further, our study population included only subjects without diabetes, who had a relatively low incidence of dyslipidemia compared to patients with diabetes. These reasons may explain the low incidence of dyslipidemia in this study cohort.

With the advancement of computational and technical methods in metabolome, both amino acid/ fatty acid derivative metabolites were approved to associated 
Table 2: Multivariate analysis of the influence of demographic and clinical characteristics on endocrine pancreatic insufficiency after distal pancreatectomy

\begin{tabular}{lcccccc}
\hline & Estimate & SE & Wald & HR & 95\% CI & $P$ value \\
\hline Female & -0.209 & 0.117 & 3.161 & 0.812 & $0.645-1.022$ & .075 \\
Dyslipidemia & 0.663 & 0.180 & 13.485 & 1.940 & $1.362-2.763$ & $<.001$ \\
Chronic pancreatitis & 0.887 & 0.128 & 47.909 & 2.428 & $1.889-3.121$ & $<.001$ \\
\hline
\end{tabular}

CI, confidence interval; DM, diabetes mellitus; HR, hazard ratio; SE, standard error, Wald, Wald chi-square.

with pathogenesis of diabetes and related risk factors [28]. Increases in plasma levels of branched-chain and aromatic amino acids have been considered not only as a marker of insulin resistance but also as a predictive risk for development of type 2 diabetes [29, 30]. Conversely, the plasma levels of glycine and glutamine were decreased in patients with insulin resistance $[31,32]$. Among the lipid metabolome, long-chain fatty acids and short \& oddchain acylcarnitines contributed to pathophysiological impairment of glucose metabolism [33, 34]. From a clinical point of view, further studies will be required to fully integrate these findings into discovery of the diabetes pathophysiology on DP patients.
One of the strengths of this study lies in its use of a nationwide population-based approach to characterize long-term changes in endocrine insufficiency after DP from high-quality databases [35-37]. However, this study also had some limitations. First, the analyzed data did not include body weight, family history, laboratory examination [28] results, or risk factors for the development of DM, such as alcohol use and other lifestyle factors. Second, coding errors may have existed in the administrative database. To decrease the incidence of coding errors, the diagnostic accuracy of comorbidities was confirmed if patients had one relevant inpatient or three outpatient ICD-9 codes separated by at least 30 days.

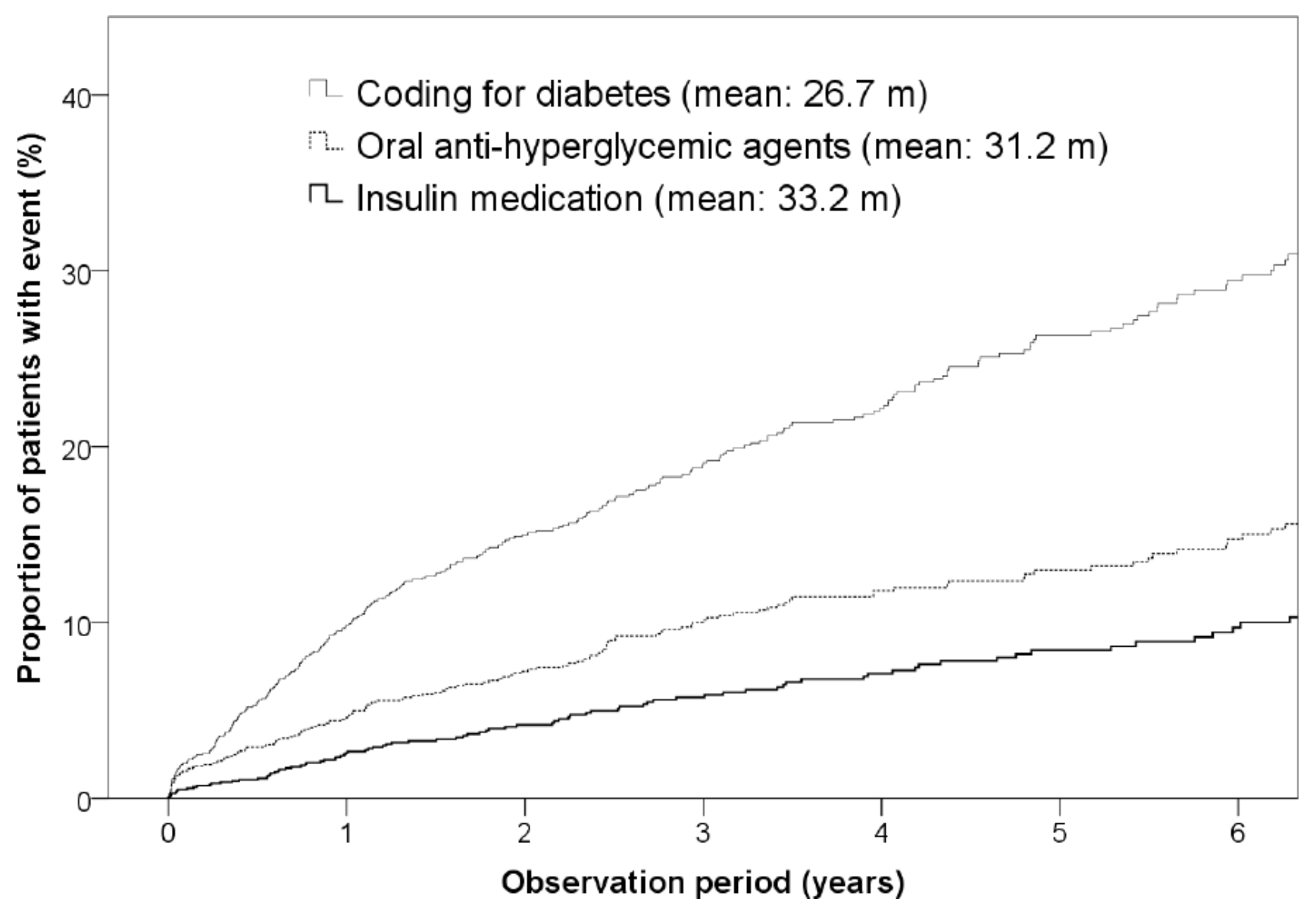

Figure 1: Proportion of patients with endocrine insufficiency requiring OHAs and insulin in pre-DP non-DM subjects by time after DP. 
Further, strict criteria $(P<0.01)$ were used to evaluate the significance of associations between independent variables and the occurrence of endocrine insufficiency. Third, we agree that some key metabolite changes (levels of lactate, fatty acids, and amino acids) are very important factors in glucose metabolism. However, these data were unavailable in the nationwide administrator database. Nationwide population-based cohort studies are crucial for determining risk factor-outcome associations. We examined subjects with DP with extended follow-up periods to investigate changes in glucose metabolism after DP. Although we identified some risk factors in this study, the mechanisms that connect risk factors and diabetes were assumed from a previous hypothesis, which should be elucidated in experimental animal models. Fourth, volume of pancreas tissue resected was a very important factor associated with development of diabetes. Pancreatic beta cells produce insulin, which is essential for glucose hemostasis [38]. Autopsy research indicated that resection of more than $65 \%$ of beta cells can cause development of overt diabetes [39]. Two observational studies used computed tomography to assess loss of pancreatic parenchyma. This study found that resection of more than $44 \%$ of pancreatic volume was associated with new-onset diabetes [40, 41]. Because of shortcomings of the nationwide database, data pertaining to loss of pancreatic tissue due to DP were not available. However, beta cells are also associated with other diseases (such as dyslipidemia, alcohol use, or pancreatitis), which can contribute to beta cell deterioration, in addition to pancreatic volume loss. On the other hand, exocrine pancreatic insufficiency (EPI) may develop after DP because the pancreas is an exocrine organ involved in food digestion. In the present study, exocrine insufficiency was defined as the use of exogenous pancreatic enzymes for more than three consecutive months $[18,42]$, and 615 $(43.6 \%)$ of the 1,410 non-diabetic patients developed new EPI after DP. Of the 312 patients with newlydiagnosed diabetes, 176 (56.4\%) also developed postDP EPI. We realized that pancreatic resection volume is a crucial factor related to the development of DM as well as EPI. However, the volumetric cut-off point for pancreatic resection in EPI may be different from that in DM. In addition, the distribution of pancreatic exocrine tissues throughout the whole pancreas may be unique to pancreatic endocrine tissues. These assist in discrimination of DM from EPI in patients with DP.

In summary, patients with dyslipidemia and $\mathrm{CP}$ had higher rates of newly-diagnosed pancreatic endocrine insufficiency among non-diabetic patients in a nationwide DP cohort. Further, more than half of the pre-DP DM patients without the use of insulin had deterioration of glucose metabolism after DP. Hence, clinicians should monitor glucose metabolism and clinical symptoms of hyperglycemia among DP patients.

\section{METHODS}

The protocol of this retrospective study was approved by the Institutional Review Board of National Taiwan University Hospital (approval no. 201606084W). The requirement to obtain informed consent was waived because sensitive information (patient identification data, medical institutions, and medical staff) was encrypted to protect privacy.

\section{Data source}

Taiwan launched a mandatory national health insurance program to offer comprehensive medical care

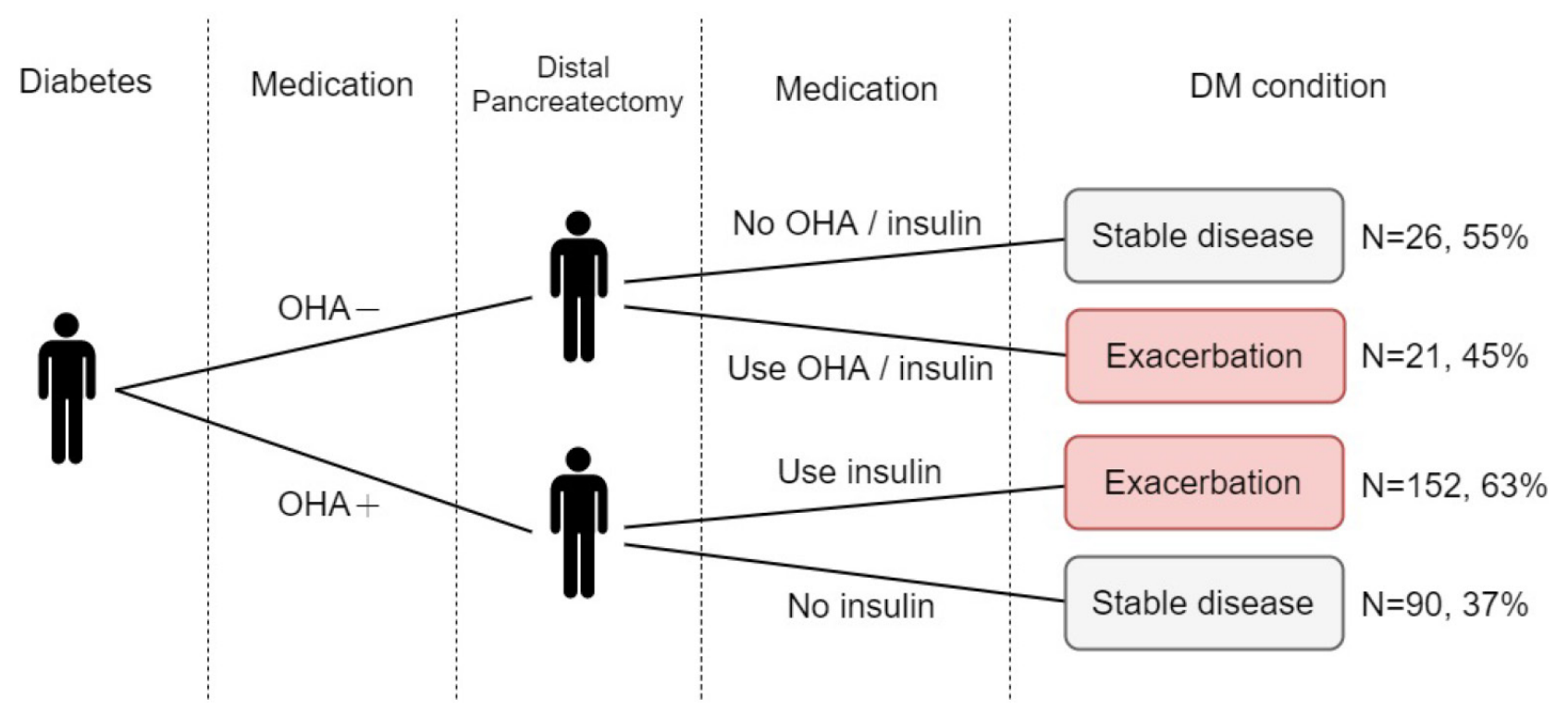

Figure 2: Deterioration of glucose metabolism in pre-distal pancreatectomy diabetes mellitus cases without the use of insulin. 
coverage to all citizens in 1995. The entire NHIRD was released for research purposes by the Collaboration Center of Health Information Application, Ministry of Health and Welfare in 2014. The NHIRD contains original claim data of more than 23 million people, which is $99.9 \%$ of the entire population of Taiwan [43]. Hence, the database provides a large and valuable population-based source for epidemiological research. The NHIRD includes all information on outpatient and inpatient claims, patient demographic information, and related information pertaining to prescriptions, procedures, and medications. All clinical diagnoses and procedures were recorded according to the International Classification of Diseases, Ninth Revision, Clinical Modification (ICD-9-CM) coding scheme.

\section{Study cohort}

A flow diagram of patient inclusion for this study is shown in Figure 3. The study cohort consisted of all patients who underwent DP (ICD-9 procedure code 52.52) between 2001 and $2010(N=2,693)$. The exclusion criteria for the current analysis were: (1) age $>20$ years $(n$ $=105)$; (2) previous pancreatic surgery $(n=213)$; and (3) follow-up of less than 6 months $(n=395)$. Thus, the final sample of this study was comprised of 1,410 non-DM and 570 DM patients who underwent DP between 2001 and 2010. Of the 570 DM subjects, 281 received insulin to control hyperglycemia. The above cases were excluded because of pre-DP poor reserve of pancreatic endocrine function.

\section{Outcome measures}

The outcomes of this study were pancreatic endocrine insufficiency of pre-DP non-DM cases and deterioration of glucose metabolism of pre-DP DM cases without the use of insulin. Endocrine insufficiency was defined as a new diagnosis of DM after DP. For the purposes of this study, DM was defined as two or more outpatient clinic visits or one admission with a diagnostic code of DM (ICD-9-CM code 250) [42]. This definition of DM was validated in a previous NHIRD study in which the sensitivity was $93.2 \%$ and the positive predictive value was $92.3 \%$ [44]. The use of oral anti-hyperglycemic agents (OHAs) and insulin was also examined from the pharmacy prescription database. Deterioration of glucose metabolism was defined as either pre-DP DM treated with an oral hypoglycemic medication, but without the

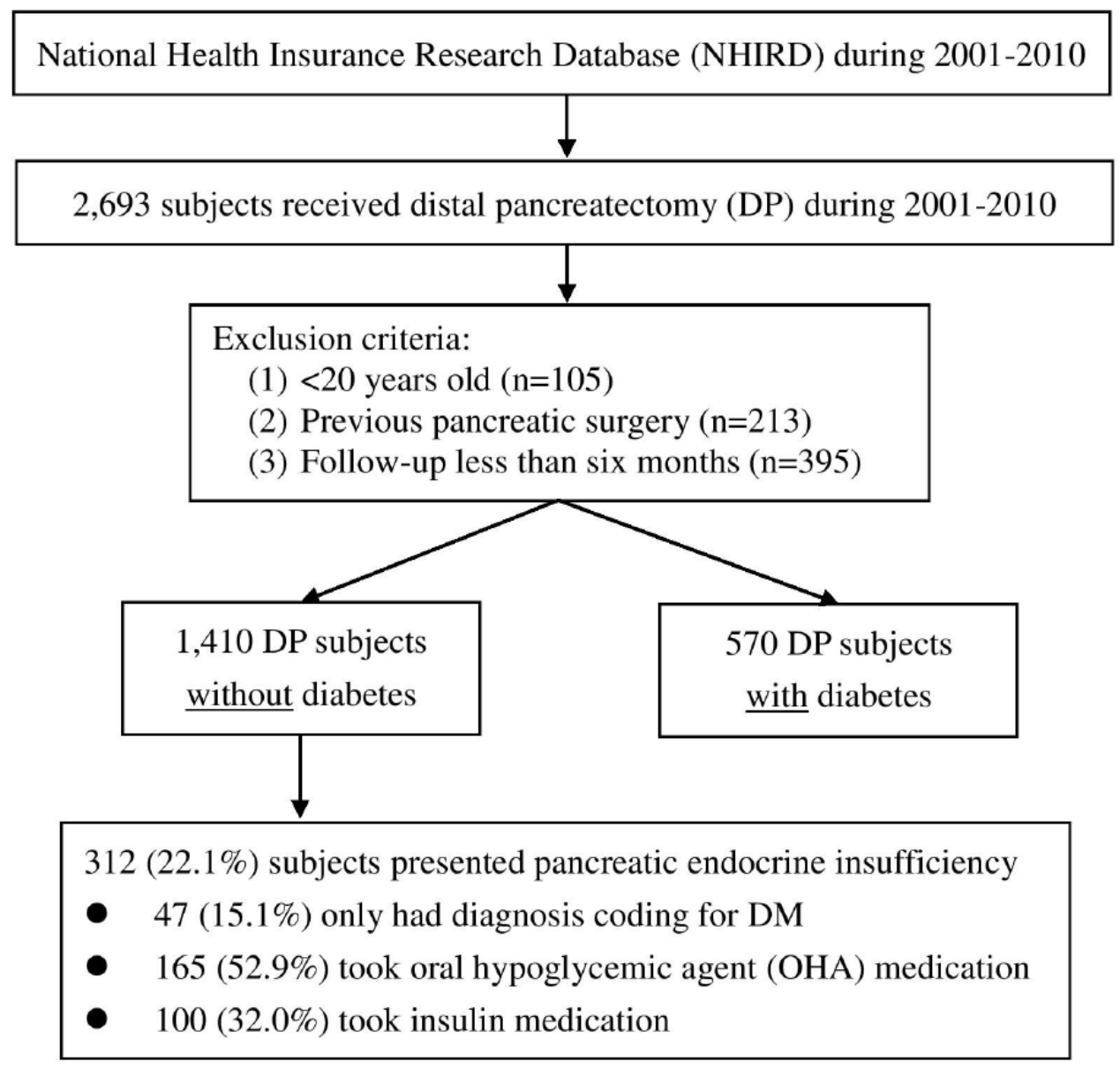

Figure 3: Study flow diagram. 
use of an anti-hyperglycemic medication (AHM; OHAs or insulin) or pre-DP DM treated with OHAs and insulin after DP.

\section{Covariates}

Comorbidity data of patients prior to DP were also collected. Comorbidities were identified by the following ICD-9-CM codes: concomitant splenectomy during DP (41.5), peptic ulcer disease (531-535), dyslipidemia (272.0-272.2), CP (577.1), renal failure (584.x-586.x), hypertension (401.x-405.x), and pancreatic cancer (157.0-157.9). The diagnostic accuracy of cancer was confirmed by the Registry for Catastrophic Illness Patient Database, a subpart of the NHIRD [42]. The Charlson comorbidity index was calculated to assess the severity of comorbidities for each patient [45]. The demographic characteristics investigated were sex, age $(\leq 49,50-64$, and $\geq 65$ years), and monthly income (New Taiwan dollar $\leq 22,798$ or $>22,798$ ).

\section{Statistical analysis}

Microsoft SQL Server 2008 was used for the management of the NHIRD and baseline data. Data analysis was performed using IBM SPSS statistical software v20 (IBM Corp., Armonk, NY, USA). All variables were calculated as percentages and quantitative variables are summarized as the mean \pm standard deviation. The Student's $t$-test was used for analysis of continuous variables. Nominal variables were analyzed using the chi-square test and Fisher exact test if the cell count was $<5$. To evaluate the independent effects of factors on endocrine insufficiency or deterioration of glucose metabolism after DP, predictors were examined with Cox regression analysis and the results are presented as hazard ratios (HRs) with $95 \%$ confidence intervals (CIs). Next, the best candidate covariates $(P$ value $<$ $0.05)$ were entered into a multivariate model. A two-sided $P$ value of $<0.01$ was considered statistically significant in the multivariate model.

\section{Abbreviations}

DP: Distal pancreatectomy; CI: confidence interval; DM: diabetes mellitus; NHIRD: National Health Insurance; Research Database; ICD-9-CM: International Classification of Disease, Ninth Revision, Clinical Modification; CCI: Charlson Comorbidity Index.

\section{ACKNOWLEDGMENTS AND FUNDING}

This study is based on the data from the Collaboration Center of Health Information Application (CCHIA), Ministry of Health and Welfare, which had no role in the study design, data collection and analysis, decision to publish, or preparation of the manuscript. This study was supported by a grant from the Ministry of Science and Technology, Taiwan (MOST 105-2221-E-002192) and from Nationa 1 Taiwan University Hospital (105$\mathrm{N} 3315$ ). The manuscript is submitted as an original article. The paper is not based on a previous communication to a society or meeting.

\section{CONFLICTS OF INTEREST}

None.

\section{REFERENCES}

1. King J, Kazanjian K, Matsumoto J, Reber HA, Yeh MW, Hines OJ, Eibl G. Distal pancreatectomy: incidence of postoperative diabetes. J Gastrointest Surg. 2008; 12:154853. https://doi.org/10.1007/s11605-008-0560-5.

2. Garcea G, Ong SL, Rajesh A, Neal CP, Pollard CA, Berry DP, Dennison AR. Cystic lesions of the pancreas. A diagnostic and management dilemma. Pancreatology. 2008; 8:236-51. https://doi.org/10.1159/000134279.

3. Valsangkar NP, Morales-Oyarvide V, Thayer SP, Ferrone CR, Wargo JA, Warshaw AL, Fernandez-del Castillo C. 851 resected cystic tumors of the pancreas: a 33-year experience at the Massachusetts General Hospital. Surgery. 2012; 152:S4-12. https://doi.org/10.1016/j.surg.2012.05.033.

4. Balcom JH, Rattner DW, Warshaw AL, Chang Y, Fernandez-del Castillo C. Ten-year experience with 733 pancreatic resections: changing indications, older patients, and decreasing length of hospitalization. Arch Surg. 2001; 136:391-8.

5. Hutchins RR, Hart RS, Pacifico M, Bradley NJ, Williamson RC. Long-term results of distal pancreatectomy for chronic pancreatitis in 90 patients. Ann Surg. 2002; 236:612-8. https://doi.org/10.1097/01.SLA.0000033039.70348.74.

6. American Diabetes Association. Diagnosis and classification of diabetes mellitus. Diabetes Care. 2012; 35:S64-71. https://doi.org/10.2337/dc12-s064.

7. American Diabetes Association. Diagnosis and classification of diabetes mellitus. Diabetes Care. 2010; 33:S62-9. https://doi.org/10.2337/dc10-S062.

8. De Bruijn KM, van Eijck CH. New-onset diabetes after distal pancreatectomy: a systematic review. Ann Surg. 2015; 261:854-61. https://doi.org/10.1097/SLA.000000000 0000819 .

9. Speicher JE, Traverso LW. Pancreatic exocrine function is preserved after distal pancreatectomy. J Gastrointest Surg. 2010; 14:1006-11. https://doi.org/10.1007/s11605-0101184-0.

10. Jalleh RP, Williamson RC. Pancreatic exocrine and endocrine function after operations for chronic pancreatitis. Ann Surg. 1992; 216:656-62. 
11. Lillemoe KD, Kaushal S, Cameron JL, Sohn TA, Pitt HA, Yeo CJ. Distal pancreatectomy: indications and outcomes in 235 patients. Ann Surg. 1999; 229:693-98. https://doi. org/10.1097/00000658-199905000-00012.

12. Chang $\mathrm{CH}$, Shau WY, Jiang YD, Li HY, Chang TJ, Sheu WH, Kwok CF, Ho LT, Chuang LM. Type 2 diabetes prevalence and incidence among adults in Taiwan during 1999-2004: a national health insurance data set study. Diabet Med. 2010; 27:636-43. https://doi.org/10.1111/ j.1464-5491.2010.03007.x.

13. Tseng $\mathrm{CH}$. Metformin and esophageal cancer risk in Taiwanese patients with type 2 diabetes mellitus. Oncotarget. 2017; 8:18802-10. https://doi.org/10.18632/ oncotarget. 13390 .

14. Conwell DL, Lee LS, Yadav D, Longnecker DS, Miller FH, Mortele KJ, Levy MJ, Kwon R, Lieb JG, Stevens T, Toskes PP, Gardner TB, Gelrud A, et al. American Pancreatic Association Practice Guidelines in Chronic Pancreatitis: evidence-based report on diagnostic guidelines. Pancreas. 2014; 43:1143-62. https://doi.org/10.1097/MPA.00000000 00000237.

15. Rotman N, Sastre B, Fagniez PL. Medial pancreatectomy for tumors of the neck of the pancreas. Surgery. 1993; 113:532-5.

16. Shoup M, Brennan MF, McWhite K, Leung DH, Klimstra $\mathrm{D}$, Conlon KC. The value of splenic preservation with distal pancreatectomy. Arch Surg. 2002; 137:164-8.

17. Malka D, Hammel P, Sauvanet A, Rufat P, O'Toole D, Bardet P, Belghiti J, Bernades P, Ruszniewski P, Levy P. Risk factors for diabetes mellitus in chronic pancreatitis. Gastroenterology. 2000; 119:1324-32.

18. Riediger H, Adam U, Fischer E, Keck T, Pfeffer F, Hopt UT, Makowiec F. Long-term outcome after resection for chronic pancreatitis in 224 patients. J Gastrointest Surg. 2007; 11:949-59. https://doi.org/10.1007/s11605-007-0155-6.

19. Schoenberg MH, Schlosser W, Ruck W, Beger HG. Distal pancreatectomy in chronic pancreatitis. Dig Surg. 1999; 16:130-36. https://doi.org/10.1159/000018705.

20. Catanzaro R, Cuffari B, Italia A, Marotta F. Exploring the metabolic syndrome: Nonalcoholic fatty pancreas disease. World J Gastroenterol. 2016; 22:7660-75. https://doi. org/10.3748/wjg.v22.i34.7660.

21. Wang CY, Ou HY, Chen MF, Chang TC, Chang CJ. Enigmatic ectopic fat: prevalence of nonalcoholic fatty pancreas disease and its associated factors in a Chinese population. J Am Heart Assoc. 2014; 3:e000297. https:// doi.org/10.1161/JAHA.113.000297.

22. Chai J, Liu P, Jin E, Su T, Zhang J, Shi K, Hong XU, Yin J, $\mathrm{Yu} \mathrm{H}$. MRI chemical shift imaging of the fat content of the pancreas and liver of patients with type 2 diabetes mellitus. Exp Ther Med. 2016; 11:476-80. https://doi.org/10.3892/ etm.2015.2925.

23. Saisho Y, Butler AE, Meier JJ, Monchamp T, AllenAuerbach M, Rizza RA, Butler PC. Pancreas volumes in humans from birth to age one hundred taking into account sex, obesity, and presence of type-2 diabetes. Clin Anat. 2007; 20:933-42. https://doi.org/10.1002/ca.20543.

24. Yamazaki H, Tsuboya T, Katanuma A, Kodama Y, Tauchi S, Dohke M, Maguchi H. Lack of Independent Association Between Fatty Pancreas and Incidence of Type 2 Diabetes: 5-Year Japanese Cohort Study. Diabetes Care. 2016; 39:1677-83. https://doi.org/10.2337/dc16-0074.

25. Smits MM, van Geenen EJ. The clinical significance of pancreatic steatosis. Nat Rev Gastroenterol Hepatol. 2011; 8:169-77. https://doi.org/10.1038/nrgastro.2011.4.

26. Rosales-Velderrain A, Bowers SP, Goldberg RF, Clarke TM, Buchanan MA, Stauffer JA, Asbun HJ. National trends in resection of the distal pancreas. World J Gastroenterol. 2012; 18:4342-9. https://doi.org/10.3748/wjg.v18.i32.4342.

27. Bao Y, Spiegelman D, Li R, Giovannucci E, Fuchs CS, Michaud DS. History of peptic ulcer disease and pancreatic cancer risk in men. Gastroenterology. 2010; 138:541-9. https://doi.org/10.1053/j.gastro.2009.09.059.

28. Gonzalez-Franquesa A, Burkart AM, Isganaitis E, Patti ME. What Have Metabolomics Approaches Taught Us About Type 2 Diabetes? Curr Diab Rep. 2016; 16:74. https://doi. org/10.1007/s11892-016-0763-1.

29. Felig P, Marliss E, Cahill GF Jr. Plasma amino acid levels and insulin secretion in obesity. N Engl J Med. 1969; 281:811-6. https://doi.org/10.1056/NEJM196910092811503.

30. Wurtz P, Soininen P, Kangas AJ, Ronnemaa T, Lehtimaki T, Kahonen M, Viikari JS, Raitakari OT, Ala-Korpela M. Branched-chain and aromatic amino acids are predictors of insulin resistance in young adults. Diabetes Care. 2013; 36:648-55. https://doi.org/10.2337/dc12-0895.

31. Cheng S, Rhee EP, Larson MG, Lewis GD, McCabe EL, Shen D, Palma MJ, Roberts LD, Dejam A, Souza AL, Deik AA, Magnusson M, Fox CS, et al. Metabolite profiling identifies pathways associated with metabolic risk in humans. Circulation. 2012; 125:2222-31. https://doi.org/10. 1161/CIRCULATIONAHA.111.067827.

32. Stancakova A, Civelek M, Saleem NK, Soininen P, Kangas AJ, Cederberg H, Paananen J, Pihlajamaki J, Bonnycastle LL, Morken MA, Boehnke M, Pajukanta P, Lusis AJ, et al. Hyperglycemia and a common variant of GCKR are associated with the levels of eight amino acids in 9,369 Finnish men. Diabetes. 2012; 61:1895-902. https://doi. org/10.2337/db11-1378.

33. Huffman KM, Shah SH, Stevens RD, Bain JR, Muehlbauer M, Slentz CA, Tanner CJ, Kuchibhatla M, Houmard JA, Newgard CB, Kraus WE. Relationships between circulating metabolic intermediates and insulin action in overweight to obese, inactive men and women. Diabetes Care. 2009; 32:1678-83. https://doi.org/10.2337/dc08-2075.

34. Yore MM, Syed I, Moraes-Vieira PM, Zhang T, Herman MA, Homan EA, Patel RT, Lee J, Chen S, Peroni OD, Dhaneshwar AS, Hammarstedt A, Smith U, et al. Discovery of a class of endogenous mammalian lipids with 
anti-diabetic and anti-inflammatory effects. Cell. 2014; 159:318-32. https://doi.org/10.1016/j.cell.2014.09.035.

35. Yu ST, Chang HY, Lin MC, Lin YH. Agreement between self-reported and health insurance claims on utilization of health care: A population study. J Clin Epidemiol. 2009; 62:1316-22. https://doi.org/10.1016/j.jclinepi.2009.01.016.

36. Wu CY, Chen YJ, Ho HJ, Hsu YC, Kuo KN, Wu MS, Lin JT. Association between nucleoside analogues and risk of hepatitis B virus-related hepatocellular carcinoma recurrence following liver resection. JAMA. 2012; 308:1906-14.

37. Ho TW, Wu JM, Yang CY, Lai HS, Lai F, Tien YW. Total gastrectomy improves glucose metabolism on gastric cancer patients: a nationwide population-based study. Surg Obes Relat Dis. 2016; 12:635-41. https://doi.org/10.1016/j. soard.2015.11.024.

38. Ahmed W, Rashid S. Functional and therapeutic potential of inulin: A comprehensive review. Crit Rev Food Sci Nutr. 2017; 0:1-13. https://doi.org/10.1080/10408398.2017.1355 775.

39. Butler AE, Janson J, Bonner-Weir S, Ritzel R, Rizza RA, Butler PC. Beta-cell deficit and increased beta-cell apoptosis in humans with type 2 diabetes. Diabetes. 2003; 52:102-10.

40. Kang JS, Jang JY, Kang MJ, Kim E, Jung W, Chang J, Shin Y, Han Y, Kim SW. Endocrine Function Impairment After
Distal Pancreatectomy: Incidence and Related Factors. World J Surg. 2016; 40:440-6. https://doi.org/10.1007/ s00268-015-3228-9.

41. Shirakawa S, Matsumoto I, Toyama H, Shinzeki M, Ajiki T, Fukumoto T, Ku Y. Pancreatic volumetric assessment as a predictor of new-onset diabetes following distal pancreatectomy. J Gastrointest Surg. 2012; 16:2212-9. https://doi.org/10.1007/s11605-012-2039-7.

42. Wu JM, Ho TW, Kuo TC, Yang CY, Lai HS, Chiang PY, Hsieh SH, Lai F, Tien YW. Glycemic Change After Pancreaticoduodenectomy: A Population-Based Study. Medicine (Baltimore). 2015; 94:e1109. https://doi. org/10.1097/MD.0000000000001109.

43. Lee YS, Jeng MJ, Tsao PC, Soong WJ, Chou P. Prognosis and Risk Factors for Congenital Airway Anomalies in Children with Congenital Heart Disease: A Nationwide Population-Based Study in Taiwan. PLoS One. 2015; 10:e0137437. https://doi.org/10.1371/journal.pone.0137437.

44. Lin CC, Lai MS, Syu CY, Chang SC, Tseng FY. Accuracy of diabetes diagnosis in health insurance claims data in Taiwan. J Formos Med Assoc. 2005; 104:157-63.

45. Charlson ME, Pompei P, Ales KL, MacKenzie CR. A new method of classifying prognostic comorbidity in longitudinal studies: development and validation. J Chronic Dis. 1987; 40:373-83. 